\title{
Metformin Synergistically Potentiates the Antitumor Effects of Imatinib in Colorectal Cancer Cells
}

\author{
Jaeryun Lee ${ }^{1}$, Deokbae Park ${ }^{2}$ and ${ }^{\dagger}$ Youngki Lee ${ }^{2}$ \\ ${ }^{1}$ Dept. of Medicine, Jeju National University School of Medicine, Jeju 690-756, Korea \\ ${ }^{2}$ Dept. of Histology, Jeju National University School of Medicine, Jeju 690-756, Korea
}

\begin{abstract}
Metformin is the most commonly prescribed anti-diabetic drug with relatively minor side effect. Substantial evidence has suggested that metformin is associated with decreased cancer risk and anticancer activity against diverse cancer cells. The tyrosine kinase inhibitor imatinib has shown powerful activity for treatment of chronic myeloid leukemia and also induces growth arrest and apoptosis in colorectal cancer cells. In this study, we tested the combination of imatinib and metformin against HCT15 colorectal cancer cells for effects on cell viability, cell cycle and autophagy. Our data show that metformin synergistically enhances the imatinib cytotoxicity in HCT15 cells as indicated by combination and drug reduction indices. We also demonstrate that the combination causes synergistic down-regulation of pERK, cell cycle arrest in $\mathrm{S}_{\text {and }} \mathrm{G}_{2} / \mathrm{M}$ phases via reduction of cyclin B1 level. Moreover, the combination resulted in autophagy induction as revealed by increased acidic vesicular organelles and cleaved form of LC3-II. Inhibition of autophagic process by chloroquine led to decreased cell viability, suggesting that induction of autophagy seems to play a cell protective role that may act against anticancer effects. In conclusion, our present data suggest that metformin in combination with imatinib might be a promising therapeutic option in colorectal cancer.
\end{abstract}

Key words : Metformin, Imatinib, HCT15 colorectal cancer cell, Cell viability

\section{INTRODUCTION}

Attempts to target the altered signaling pathways at molecular level have been proven to be effective for the treatment of cancer. Kinases in signal transduction process are closely implicated in tumor cell proliferation and survival, which has led to the development of small kinase inhibitors for cancer intervention. Imatinib, a small-molecule tyrosine kinase inhibitor (TKI) targeting the fusion protein of BCR-ABL kinase found in chronic myeloid leukemia (CML), has been widely used in the CML treatment, exhibiting up to $80 \%$ response rate (Druker et al., 1996; Zhang et al., 2009). However, despite this exciting therapeutic efficacy, significant challenges are faced due to drug resistance and side effects of imatinib, resulting in high relapse rate and dose reduction respectively. Although second-generation TKIs such as dasatinib (Hochhaus et al., 2008) and nilotinib (Saglio et al., 2010) have been developed to overcome imatinib resistance and improve the prognosis of CML patients, resistance to these novel inhibitors still arises partly from the emergence of BCR-ABL mutant clones (O'Hare et al., 2011). Therefore, it has been a challenging theme to over-

\footnotetext{
Manuscript received April 12, 2017, Received in revised form April 15, 2017, Accepted April 18, 2017

$\dagger$ Corresponding Author : Youngki Lee, Department of Histology, Jeju National University School of Medicine, 66 Jejudaehakno, Jeju 690-756, Korea. Tel: +82-64-754-3826, Fax: +82-64-702-2687, E-mail: yklee38@jejunu.ac.kr

This is an Open Access article distributed under the terms of the Creative Commons Attribution Non-Commercial License (http:// creativecommons.org/licenses/by-nc/3.0) which permits unrestricted non-commercial use, distribution, and reproduction in any medium, provided the original work is properly cited.
} 
come this compromised effectiveness of imatinib as a single agent for successful treatment outcome in the clinic.

In addition to its inhibition of BCR-ABL tyrosine kinases in CML, imatinib targets selectively other receptor tyrosine kinases such as stem cell factor receptor (c-Kit) and platelet-derived growth factor (PDGF) receptor, and is currently used for the treatment of gastrointestinal stromal tumor (GIST) harboring c-Kit mutation (Joensuu et al., 2001; De Giorgi \& Verweij, 2005). Several studies demonstrated that Abl kinases are tyrosine phosphorylated and activated in solid tumors and imatinib promotes apoptosis and inhibits growth of various cancer cells including colorectal cancer (CRC) cells (Attoub et al., 2002; Stahtea et al., 2007; Popow-Wozniak et al., 2011; Abdel-Aziz et al., 2015). Furthermore, recent reports suggested that imatinib suppresses cell proliferation in intestinal adenomas and CRC cell lines via the regulation of Abl-cyclin D1 pathway (Genander et al., 2009; Kundu et al., 2015).

Metformin, a biguanide derivative, is a widely prescribed and well-tolerated first-line drug for type II diabetes mellitus. Metformin lowers the blood glucose level by inhibiting hepatic gluconeogenesis and increasing glucose uptake in skeletal muscles, which lead to a decline in circulating insulin levels (Shaw et al., 2005). Several retrospective studies have described that metformin treatment in diabetic patients significantly reduced the risk of cancer incidence and metformin use in CRC patients with diabetes is associated with decreased mortality, suggesting a potential role of metformin as an anticancer agent (Evans et al., 2005; Lee et al., 2011). In many preclinical studies, metformin suppressed cellular proliferation, caused apoptosis, induced cell cycle arrest, and decreased the incidence and growth of experimental tumors (Isakovic et al., 2007; Ben Sahra et al., 2008; Tomimoto et al., 2008; Alimova et al., 2009). Moreover, combinatory treatment of metformin and other chemotherapeutic drugs showed the synergistic anti-cancer effects in CRC cells (Zhang et al., 2013; Nanglia- Makker et al., 2014), demonstrating the possibility of decreasing the dose of chemotherapeutic drugs with severe side effects.

The present study was undertaken to investigate whether metformin could be used in conjunction with imatinib to inhibit the growth of HCT15 CRC cells and to delineate its mechanisms of regulation. Herein, we observed synergistic growth inhibition of HCT15 CRC cells with the combination of imatinib and metformin, and described synergistic down-regulation of pERK, cell cycle arrest, and induction of autophagy as the mechanism explaining effects of the combination.

\section{MATERIAL AND METHODS}

\section{Reagents and cell culture}

Imatinib (also known as Gleevec) and metformin were purchased from Sigma-Aldrich (St. Louis, Mo, USA). Imatinib was dissolved in DMSO to a concentration of 50 $\mathrm{mM}$ and additionally in DMEM media to a working stock concentration of $100 \mu \mathrm{M}$. Metformin was dissolved in phosphate buffered saline to a working concentration of $100 \mathrm{mM}$. The human colorectal cancer cell line HCT15 was obtained from ATCC (Rockville, MD, USA). The cells were maintained and grown in Dulbecco's modified Eagle's medium ( $1.0 \mathrm{~g}$ glucose/L) supplemented with $10 \%$ fetal bovine serum (Gibco BRL, Rockville, MD, USA) at $37^{\circ} \mathrm{C}$ in a humidified atmosphere consisting of $5 \% \mathrm{CO}_{2}$ and $95 \%$ air. Cells were regularly tested for mycoplasma contamination by treating $5 \mu \mathrm{g} / \mathrm{mL}$ of Plasmocin (Invivo Gen, San Diego, CA, USA). Acridine orange, chloroquine and 3-(4,5-dimethylthiazol-2-yl)-2,5-diphenyl tetra-zolium bromide (MTT) were all purchased from Sigma-Aldrich.

\section{Cell viability assay}

Cell viability was determined by using MTT method as described previously (Park \& Lee, 2014). HCT15 cells were harvested and seeded in 24-well plates at a concentration of $5 \times 10^{4}$ cells/well, After $24 \mathrm{hr}$, cells were treated with varying concentration of imatinib $(2.5-40 \mu \mathrm{M})$, metformin 
(0.25-4 mM), their combination or vehicle control for 48 hr. Results represent the median of 3 separate experiments each conducted in quadruplicate. The $\mathrm{IC}_{50}$ values, combination index (CI) and dose reduction index (DRI) were calculated by using CompuSyn software (ComboSyn Inc, Paramus, NJ, USA). The resulting CI is a quantitative measure of the degree of drugs interaction. If $\mathrm{CI}<1$, it indicates synergism; if $\mathrm{CI}=1$, it indicates additive effect; if $\mathrm{CI}>1$, it indicates antagonism. DRI denotes how many folds of dose reduction are allowed for each drug due to synergism when compared with the dose of each drug alone.

\section{Western blotting}

Western blotting assays were performed as previously described (Song et al., 2011) using the following primary antibodies: cyclin D1, cyclin A, cyclin B1, ERK, pERK $\left(\mathrm{Tyr}^{204}\right.$ ) (all from Santa Cruz Biotechnology, Santa Cruz, CA, USA), and LC3B (Cell Signaling, Beverly, MA, USA). After incubation with secondary antibodies conjugated to horseradish peroxidase (Cell Signaling), enhanced chemiluminescence was used for detection of immunoreactivity (Santa Cruz Biotechnology). $\beta$-actin (Cell Signaling) served as a loading control.

\section{Cell cycle analysis}

HCT15 cells were plated onto $60 \mathrm{~mm}$ dishes and treated with different concentrations of metformin, imatinib, the combination and vehicle control for $24 \mathrm{hr}$. Cells were harvested by treating trypsin-EDTA for $5 \mathrm{~min}$ at $37^{\circ} \mathrm{C}$, washed with PBS and fixed overnight in $50 \%$ ethanol at $4{ }^{\circ} \mathrm{C}$. Fixed cells were washed with PBS and incubated with RNase $(200 \mu \mathrm{g} / \mathrm{mL})$ for $30 \mathrm{~min}$ at $37^{\circ} \mathrm{C}$, and followed by propidium iodide staining. Cells were analyzed by using BD FACSCalibur Flow Cytometry System and data were analyzed by using CellQuest software (Becton Dickinson).

\section{Acridine orange staining}

To detect acidic vesicular organelles which consist pre- dominantly of autophagosome and autolysosome and appear following autophagy induction, we carried out vital staining with acridine orange after treatment of metformin or imatinib. Briefly cells were washed twice with PBS, stained with acridine orange $(1 \mu \mathrm{g} / \mathrm{mL})$ in HBSS containing 5\% FBS for $15 \mathrm{~min}$ and then observed with fluorescence microscope.

\section{Colony formation assay}

Cells were seeded in 6 well plates at a density of 200 cells per well. On the second day, cells were treated with metformin or imatinib. Every three days, medium was changed with fresh medium containing the corresponding concentration of the drugs. After twelve day treatment, cell colonies were washed twice with cold PBS and then fixed with ice-cold $100 \%$ methanol. Cell colonies were stained with $0.1 \%$ crystal violet in $20 \%$ methanol and taken pictures with digital camera.

\section{Statistical analysis}

Data were expressed in the form of mean \pm SEM. The statistical analysis was done by using Student's $t$ Test. Differences between means were considered as significant when yielding $p<0.05$.

\section{RESULTS}

\section{Effect of imatinib, metformin and combination on} the cell viability in HCT15 cells

To evaluate the response of HCT15 CRC cells to imatinib and metformin, we first treated HCT15 cells with various concentrations of imatinib and metformin for $48 \mathrm{hr}$, and cell viability was determined by using MTT assay. As shown in Fig. 1A and B, imatinib and metformin inhibited cell viability in a concentration-dependent manner. $\mathrm{IC}_{50}$ values of imatinib and metformin were $38.2 \mu \mathrm{M}$ and 2.7 $\mathrm{mM}$, respectively. Next, we analyzed the effect of imatinib in combination with metformin on cell growth by deter- 
(A)

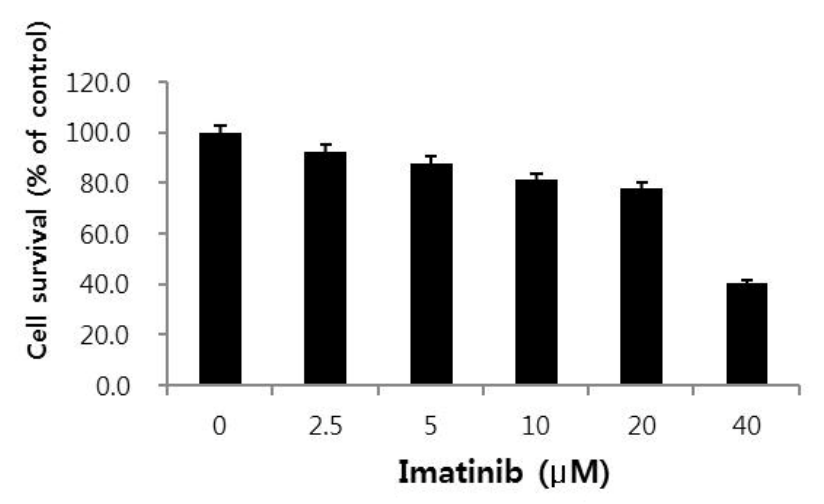

(C)

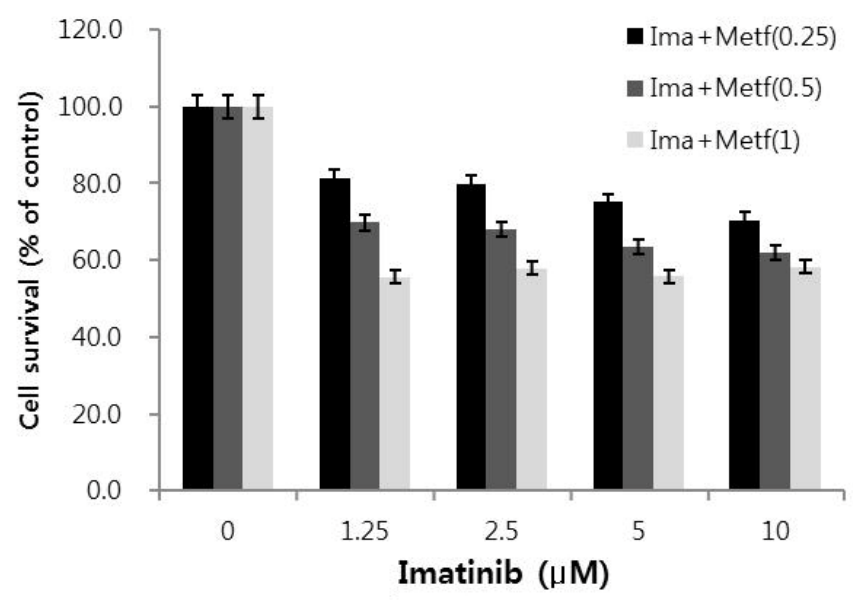

(B)

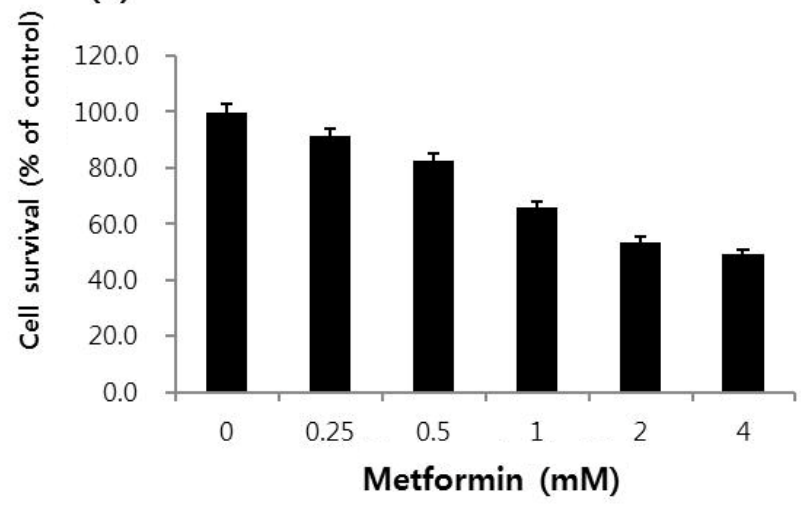

(D)

Fig. 1. Effects of imatinib, metformin and their combination on HCT15 colorectal cancer cells. (A-C) Cells were seeded at $5 \times 10^{4}$ cells $/$ well $(0.5 \mathrm{~mL})$ in 24 -well culture plates, incubated for $24 \mathrm{hr}$ and then treated with imatinib (A), metformin (B) and the combination of both (C) for $48 \mathrm{hr}$. Cell viability was measured by MTT assay. The viability of control cells was regarded as $100 \%$. ( $\mathrm{n}=3$, bars represents SEM). (D) Western blot analyses for pERK and ERK proteins, the key effector proteins of RAF/MEK/ERK signaling pathway. Cells were treated with imatinib $(10 \mu \mathrm{M})$, metformin $(1 \mathrm{mM})$ and their combination for $24 \mathrm{hr}$. $\beta$-actin was included as a loading control.

mining the type of interaction between two drugs. Imatinib and metformin were combined in non-constant ratios, in which the fixed dose of metformin $(0.25,0.5$ or $1 \mathrm{mM})$ were co-treated with different concentrations of imatinib $(1.25-10 \mu \mathrm{M})$. As shown in Fig 1C, anti-proliferative activity of imatinib was augmented in proportion to increasing doses of metformin. The combination index $(\mathrm{CI})$ values ranged from 0.51 to 0.86 , indicating synergism according to the method of Chou-Talalay (Chou \& Talalay, 1981) (Table 1). The combination also showed that the values of drug reduction index (DRI) were always above 1 at any combination points of two drugs (Table 2). We next screened the change of pERK protein, one of the key regulator proteins in signal transduction pathway, by Western blot assay. Metformin and imatinib each induced a remarkable reduction in pERK, and the combination of metformin and imatinib caused almost complete suppression of pERK level (Fig. 1D).

\section{Imatinib, metformin and combination induce cell} cycle arrest

Since imatinib, metform and their combination decreases 
Table 1. Synergistic interaction between imatinib (Ima) and metformin (Metf) in HCT15 cells as revealed by combination index (CI) values.

\begin{tabular}{cccccc}
\hline \hline Ima $(\mu \mathrm{M})$ & 1.25 & 2.5 & 5 & 10 & Type of interaction \\
\hline CI at 0.25 mM Metf & 0.52 & 0.56 & 0.58 & 0.71 & Synergistic \\
CI at 0.5 mM Metf & 0.51 & 0.52 & 0.52 & 0.66 & Synergistic \\
CI at 1 mM Metf & 0.51 & 0.6 & 0.63 & 0.86 & Synergistic \\
\hline
\end{tabular}

CI values were calculated by using the CompuSyn software according to the recommendations of Chou-Talaly.

Table 2. Dose reduction index (DRI) values of combination treatments of imatinib (Ima) and metformin (Metf) in HCT15 cells.

\begin{tabular}{|c|c|c|c|c|c|c|c|c|}
\hline \multirow{2}{*}{ Ima (uM) } & \multicolumn{2}{|c|}{1.25} & \multicolumn{2}{|c|}{2.5} & \multicolumn{2}{|c|}{5} & \multicolumn{2}{|c|}{10} \\
\hline & Metf & Ima & Metf & Ima & Metf & Ima & Metf & Ima \\
\hline DRI at $0.25 \mathrm{mM}$ Metf & 2.33 & 11.2 & 2.54 & 5.92 & 3.36 & 3.56 & 4.33 & 2.11 \\
\hline DRI at $0.5 \mathrm{mM}$ Metf & 2.22 & 17.1 & 2.42 & 9.08 & 3 & 5.22 & 3.22 & 2.73 \\
\hline DRI at $1 \mathrm{mM}$ Metf & 2.11 & 26.14 & 1.91 & 12.25 & 2.09 & 6.51 & 1.88 & 3.03 \\
\hline
\end{tabular}

DRI values denote how many folds of dose reduction are allowed for each drug due to synergism when compared with the dose of each drug alone.

cell viability, we explored whether these results are attributed to the changes of cell cycle distribution. Cell cycle analysis of HCT15 cells by flow cytometry using PI staining is shown in Fig. 2. After treatment of metformin (1 $\mathrm{mM}$ ) alone for $24 \mathrm{hr}$, the percentage of HCT15 cells in S phase was increased from $17.9 \%$ of control to $26.7 \%$. The increase of cell population in $\mathrm{S}$ phase is accompanied by a reduction in $\mathrm{G}_{1}$ phase, indicating that metformin induced cell cycle arrest in S phase. Imatinib $(10 \mu \mathrm{M})$ caused cell cycle arrest in $\mathrm{G}_{2} / \mathrm{M}$ phase and to lesser extent in $\mathrm{S}$ phase. Combination treatment of metformin and imatinib resulted in similar pattern of cell cycle distribution as treated with imatinib alone. We further monitored the changes of proteins involved in cell cycle regulation using Western blot. As shown in Fig. 3, while there is no apparent alteration in cyclin $\mathrm{D}_{1}$ and $\mathrm{A}$ as compared to control, cyclin $\mathrm{B} 1$ levels were remarkably reduced by imatinib, metfromin and their combination treatment.

\section{Effect of imatinib, metformin and combination on} autophagy induction

Substantial evidence has been accumulating to reveal that most of chemotherapeutic and molecular targeted agents employed in cancer therapy cause the activation of autophagy in cancer cells (Sui et al., 2013). Therefore, we examined the effect of imatinib, metformin and their combination on autophagy induction. The lysosomotropic agent acridine orange (AO) accumulates in the acidic vesicular organelles (AVOs) such as autophagosomes and autolysosomes, which are formed after the initiation of autophagy. When excited with blue light, AO emits red fluorescence in AVOs and green fluorescence in cytoplasm and nucleus (Takeuchi et al., 2005). It has been also suggested that the microtubule-associated protein light chain 3 (LC3) is a novel marker of autophagy activation. Upon autophagy induction the cytosolic full-length form of LC3$1(16 \mathrm{kDa})$ is processed to the cleaved autophagosome-bound 

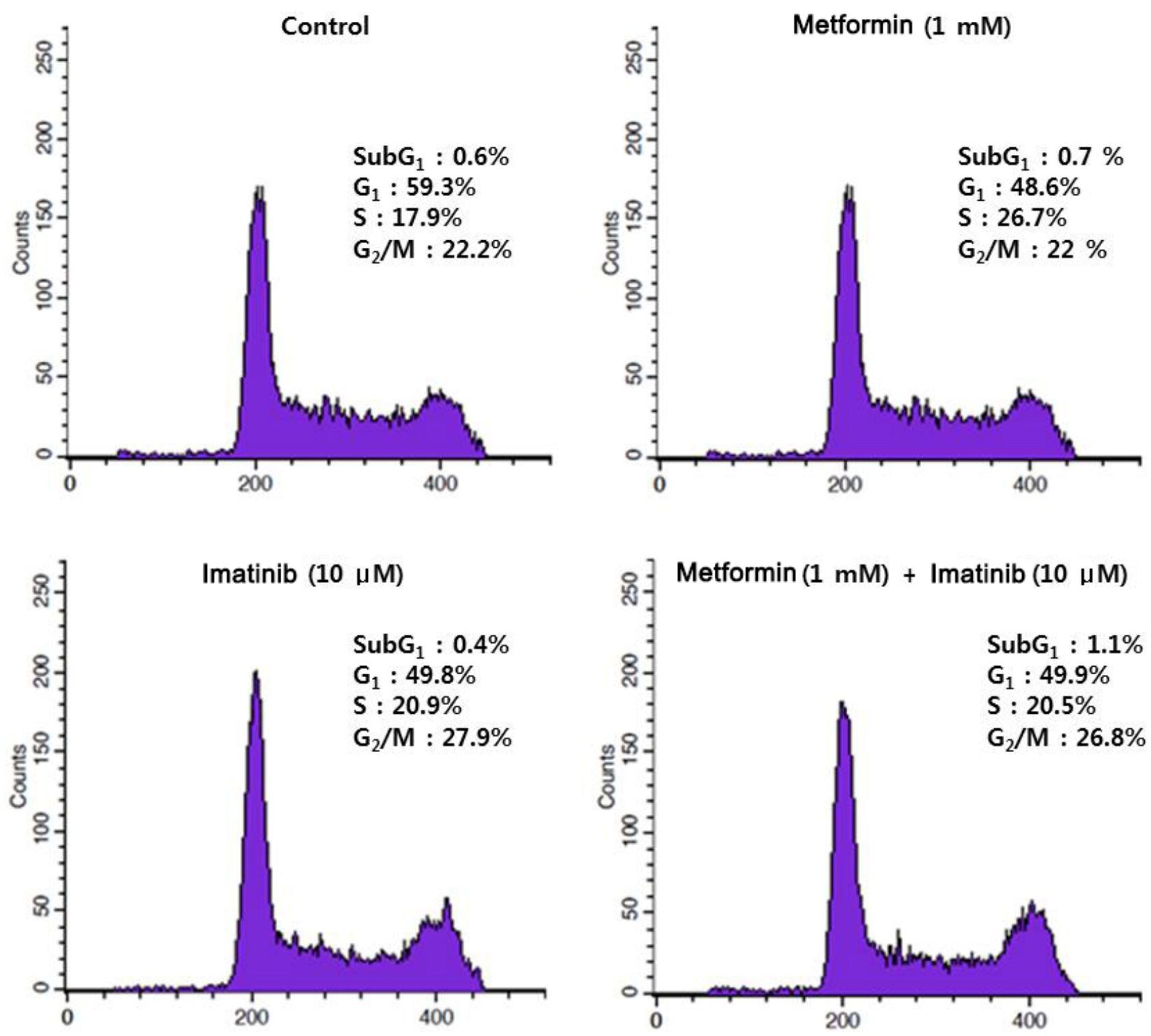

Fig. 2. Effect of imatinib, metformin and their combination on cell cycle progression in HCT15 cells. Cells were exposed to the indicated concentrations for $24 \mathrm{hr}$ and cell cycle distributions were analyzed by flow cytometry.

form of LC3-II (14 kDa) through lipidation to be associated with autophagic vacuoles (Li et al., 2013). In our study, metformin alone showed a little increased red fluorescent AVOs formation while imatinib and the combination of metformin and imatinib led to the markedly increased red fluorescent AVOs in the cytoplasm compared to control cells (Fig. 4A). Western blot analysis revealed that metformin did not show the increase of the lipidated LC3-II form, whereas imatinib and the combination treatments showed the increased level of LC3-II form, consistent with the results observed in AO staining (Fig. 4B).

4. Inhibition of autophagy enhances the antitumor activity of imatinib, metformin and combination

It has been suggested that many anti-cancer therapeutic agents induce autopahgy, which acts as either prosurvival or prodeath role of cancer cells (Yang et al., 2011). Thus we asked how the inhibition of autophagy affects the anti- 


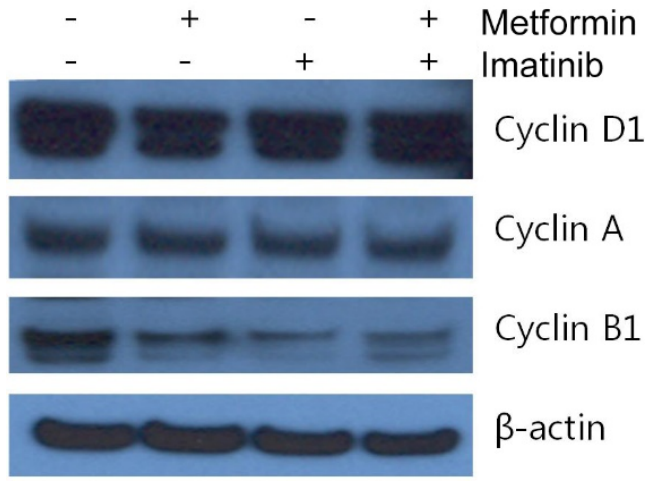

Fig. 3. Western blot analyses to reveal the effect of imatinib, metformin and their combination on cell cycle-specific regulatory proteins. Cells were treated with imatinib $(10 \mu \mathrm{M})$, metformin $(1$ $\mathrm{mM}$ ) and their combination for $24 \mathrm{hr}$. $\beta$-actin was used as a loading control.

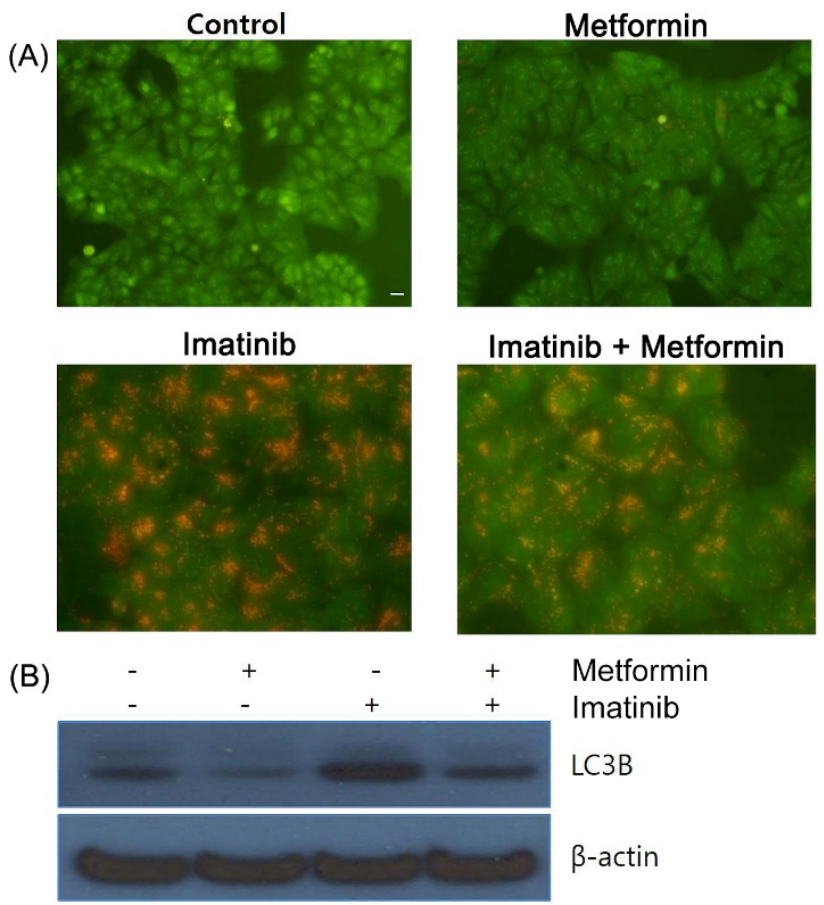

Fig. 4. Induction of autophagy in response to imatinib and/or metformin in HCT 15 CRC cells. (A) Acridine orange staining. HCT15 cells were seeded in 24-well culture dish and then treated with imatinib $(10 \mu \mathrm{M})$ and/or metformin $(1 \mathrm{mM})$ for 24 hr. Cells were stained with acridine orange and visualized under red filter fluorescent microscope. Bar, $10 \mu \mathrm{M}$. (B) Western blot assay for the detection of LC3. $\beta$-actin was used as a loading control. tumor activity in our treatment regimen. To this end, we employed a lysosmotropic agent chloroquine (CQ), which interferes with the fusion between autophagosomes and lysosome and thus widely used as an autophagy inhibitor (Mizushima et al., 2010). As shown in Fig. 5, co-treatment of metforim, imatinib or their combination with CQ resulted in more decreased cell viability compared to that observed in treatment of metformin, imatinib or combination alone.

\section{Metformin augments the inhibitory effect of imati-} nib on the colony formation in HCT15 cells

To further confirm the synergistic effect of imatinib in combination with metformin, we tested the long term effect of this drug combination in a 12-day colony formation assay. As shown in Fig. 6, imatinib or metformin alone at the tested doses partially inhibited the growth of colony formation. However the combination of imatinib and metformin potentiated the inhibitory effect on the formation and growth of colonies as compared with either agent alone. Thus, these results further support the synergistic anticancer effect of imatinib and metformin combination treatment

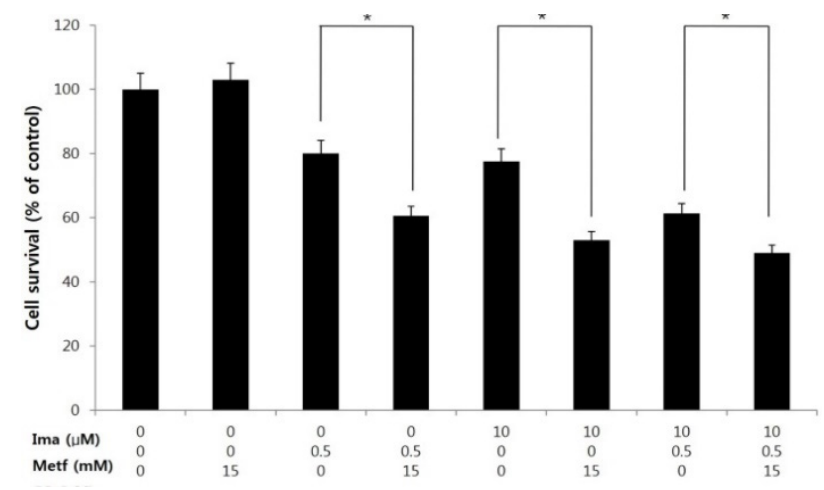

Fig. 5. Inhibition of autophagy enhances the anticancer effect of imatinib and/or metformin in HCT15 CRC cells. Cells were treated with imatinib and/ or metformin in combination with CQ as indicated. 48 $\mathrm{hr}$ after treatment, cell viability was then analyzed by MTT assay. Experiments were repeated three times. Error bars, SEM. *, $p<0.05$. 


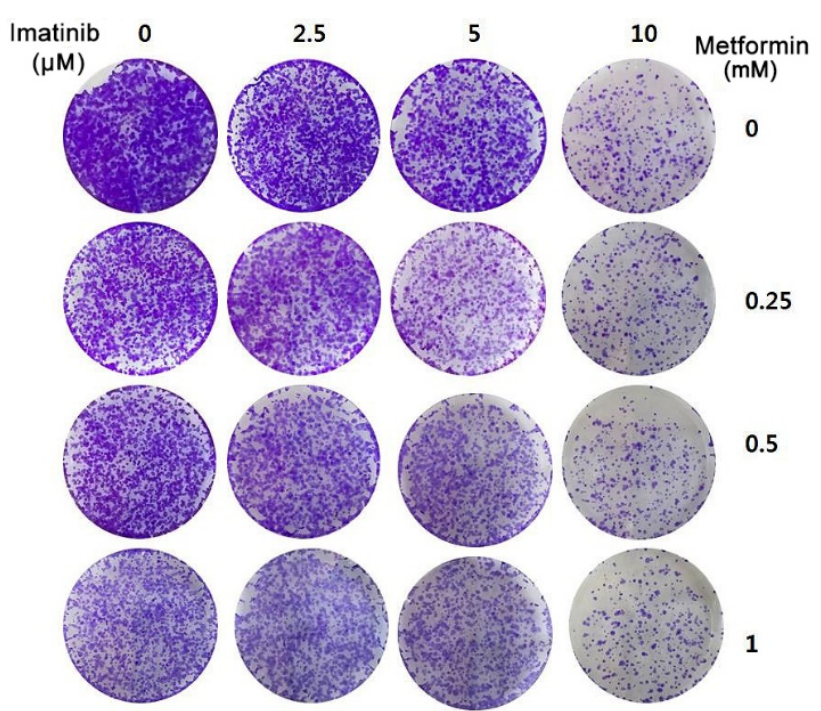

Fig. 6. Combinatory treatment of imatinib with metformin results in enhanced inhibition of colony formation in HCT15 CRC cells. Cells were seeded in 24-well plates at a density of 200 cells per well. After $24 \mathrm{hr}$ cells were treated with the indicated concentrations of imatinib or metformin. The same treatments were every 3 days. After 12 day treatment, cell colonies were stained with crystal violet dye and taken pictures with digital camera.

in HCT15 CRC cells.

\section{DISCUSSION}

The tyrosine kinase inhibitor imatinib has shown a substantial therapeutic activity in patients with chronic myeloid leukemia (CML), a disease resulting from mutated BCR-Abl kinase. Imatinib also inhibits the catalytic activity of PDGF receptor and c-kit receptor kinase. Therefore, imatinib is successfully used for the treatment of GIST with mutated c-kit tyrosine kinase and several studies have suggested that imatinib inhibits cell proliferation and induces apoptosis in CRC cells (Attoub et al., 2002; Stahtea et al., 2007; Popow-Wozniak et al., 2011; Abdel-Aziz et al., 2015). However, despite high response rate of imatinib in CML and GIST patients, significant drug resistance and side effects have become a challenging theme in the clinic. As a candidate to overcome these problems in cancer therapeutics, the biguanide metformin prescribed widely for the diabetes treatment with well tolerable side effects has been tested as a single agent or combination treatment with other drugs since metformin shows the antiproliferative and proapoptotic activity in various cancer cells.

In the present study, we evaluated the effects of metformin, imatinib and their combination in HCT15 CRC cell line, and showed dose- and time-dependent growth inhibitory effect of imatinib and metformin. In addition, the combination resulted in synergistic growth inhibitory effects in HCT15 cells as revealed in CI and DRI values. Recently, Shi et al (2015) reported that metformin also potentiates the anticancer activity of imatinib in CML cells. To elucidate the underlying mechanism for the synergism of the imatinib and metformin combination, we explored changes in the levels of pERK1/2. Interestingly, our study showed that metformin alone significantly suppressed pERK level. Metformin is known to inhibit mitochondrial complex I (NADH dehydrogenase) activity in the electron transport chain, which in turn increases the cellular AMP/ ATP ratio. This high AMP/ATP ratio activates the phosphorylation of AMPK, a master energy sensor within cell, and then pAMPK inhibits mTOR signaling by activating TSC2 and subsequently inhibiting Rheb (Quinn et al., 2013; Wheaton et al., 2014). Therefore we anticipated that metformin might increase pERK, considering that RASRAF-MEK-ERK and PI3K-AKT-mTOR pathways negatively regulates each other's activity and mTOR inhibitorbased therapy often resulted in drug resistance due to the activation of ERK (Mendoza et al., 2011). Currently, the reason is yet unclear, but there are some reports showing the decrease of $\mathrm{pE}$.

RK following metformin treatment (Niehr et al., 2011). In addition, Alimova et al (2009) suggested that the high concentration of metformin inhibits the epidermal growth factor receptor activity, which leads to reduction of pERK 
in breast cancer cells. The exact mechanism of anticancer activity of metformin at molecular level is a matter of debate, and there is a conflicting issue on the high doses of metformin (1-20 mM) used in vitro cell culture study compared to serum levels $(6-30 \mu \mathrm{M})$ observed in diabetic patients to whom metformin is prescribed. One possible explanation for this may be that cultured cell lines have not the cationic transporter OCT1 to enter metformin into cytoplasm (Niehr et al., 2011). Another is the positively charged metformin is accumulated in tissues or within mitochondria. This might reach the local concentration of metformin up to 1,000 fold higher than the serum levels, similar doses to those used in cell culture models (Wilcock \& Bailey, 1994).

Molecular targeted agents for cancer therapeutics are known to induce cell cycle arrest and much attention has been paid to the control of cell cycle in the field of oncology. In our current study, flow cytometry showed that metformin, imatinib and the combination caused an increase in $\mathrm{S}$ phase or $\mathrm{G}_{2} / \mathrm{M}$ phase population $24 \mathrm{hr}$ after treatment. This is in good agreement with the result of western blot analysis showing that cyclin B1 levels were markedly reduced with no apparent changes of cyclin D1 and cyclin A levels after treatments of metformin, imatinib and the combination, since the accumulation of cyclin $\mathrm{B} 1$ protein begins at the $\mathrm{S}$ phase and reaches the maximal level at $\mathrm{G}_{2} / \mathrm{M}$ phase (Norbury \& Nurse, 1992). In contrast, several studies described that Abl tyrosine kinase regulates cell cycle and blocking of Abl tyrosine kinase with imatinib reduces cell proliferation via depletion of cyclinD1 and hence leads to $G_{1}$ arrest of cell cycle (Genander et al., 2009). However, a report with CML cells showed that imatinib brings about a transient $\mathrm{G}_{1}$ phase accumulation and $\mathrm{S}$ phase depletion peaking at $12 \mathrm{hr}$ after treatment followed by a progressive decrease of $\mathrm{G}_{1}$ phase content and accumulation in S phase at $24 \mathrm{hr}$ (Huguet et al., 2008). Thus, the discrepancy of our results with others seems to reside in the time-dependent changes in cell cycle distribu- tion after imatinib treatment and further detailed analysis is required to delineate the precise temporal pattern of cell cycle distribution after imatinib treatment in HCT15 CRC cells.

Autophagy is a lysosomal catabolic mechanism which is required for the maintenance of cellular homeostasis. Cellular autophagy is induced in environmental or metabolic stress conditions such as nutrient deprivation or serum withdrawal. Many cancer therapeutic agents, either chemotherapeutic or molecular targeted drugs, have been known to induce autophagy and imatinib also activates autophagy in various cancer cells including CRC cells (Abdel-Aziz et al., 2015). Our present study also showed that the anticancer drug imatinib and its combination with metformin activated autophagy in HCT15 CRC cells. Although increasing evidence is accumulating to show the importance of autophagy in cancer therapeutics, the role of autophagy in cancer is still controversial. Autophagy induced following cancer therapy often behaves like a double-edged sword by increasing or diminishing the anticancer activity of drugs. Autophagy induction in response to cancer therapy can act as a cell protective mechanism causing drug resistance of cancer cells. Therefore, inhibition of autophagy can reverse the drug resistance and enhance the cytotoxicity of anticancer drugs. On the other hand, autophagy may give rise to cell death, a second type of programmed cell death (autophagic cell death). In this latter case, autophagy inhibition would increase the viability of cancer cells (Sui et al., 2013). Thus it is important to determine whether autophagy is induced in cancer cells in response to cancer therapy and the induced autophagy serves as cell protective or cell destructive role. In the present study, we showed that inhibition of autophagy induced by metformin, imatinib and the combination augments the cytotoxicity by diminishing the cell viability. This indicates that the induced autophagy acts as cell survival mechanism in HCT15 CRC cells. Our result is consistent with other reports showing that autophagy inhibition by different au- 
tophagic inhibitors potentiates the anticancer effect of imatinib in several cancer cells (Crowley et al., 2013).

Taken together, our study reveals that metformin and imatinib inhibits cell viability in dose-dependent manner and metformin synergistically augments the anticancer activity of imatinib in HCT15 CRC cells. Moreover, we showed that autophagy is activated in response to metformin, imatinib and the combination, and the blockage of autophagy resulted in the decrease of cell viability. Thus, our findings suggest that metformin may be used clinically to enhance the antitumor effect of imatinib and inhibition of autophagy can be a potential strategy to increase therapeutic efficacy of imatinib in combination with metformin. Further comprehensive studies are required to examine in vivo synergistic antitumor effect of imatinib and metformin combination therapy for the clinical application.

\section{ACKOWLEDGEMENT}

This research was supported by the 2016 scientific promotion program funded by Jeju National University.

\section{REFERENCES}

Abdel-Aziz AK, Azab SSE, Youssef SS, El-Sayed AM, ElDemerdash E, Shouman S (2015) Modulation of imatinib cytotoxicity by selenite in HCT116 colorectal cancer cells. Basic Clin Pharmaco Toxicol 116:37-46.

Alimova IN, Liu B, Fan Z, Edgerton SM, Dillon T, Lind SE, Thor AD (2009) Metformin inhibits breast cancer cell growth, colony formation and cell cycle arrest in vitro. Cell Cycle 8:909-915.

Attoub S, Rivat C, Rodrigues S, Bocxlaer SV, Bedin M, Bruyneel E, Louvet C, Kornprobst M, Andre' T, Mareel M, Mester J, Gespach C (2002) The c-kit tyrosine kinase inhibitor STI571 for colorectal cancer therapy. Cancer Res 62:4879-4883.

Ben Sahra I, Laurent K, Loubat A, Giorgetti-Peraldi S,
Colosetti P, Auberger P, Le Marchand-Brustel Y, Bost F (2008) The antidiabetic drug metformin exerts an antitumoral effect in vitro and in vivo through a decrease of cyclin D1 level. Oncogene 27:3576-3586.

Chou TC, Talalay P (1981) Generalized equations for the analysis of inhibitions of Michaelis-Menton and higher-order kinetic systems with two or more mutually exclusive and nonexclusive inhibitors. Eur J Biochem 115:207-216.

Crowley LC, O'Donovan TR, Nyhan MJ, JMcKenna SL (2013) Pharmacological agents with inherent anti-autophagic activity improve the cytotoxicity of imatinib. Oncol Rep 29:2261-2268.

De Giorgi U, Verweij J (2005) Imatinib and gastrointestinal stromal tumors: Where do we go from here? Mol Cancer Ther 4:495-501.

Druker BJ, Tamura S, Buchdunger E, Ohno S, Segal GM, Fanning S, Zimmerman J, Lydon NB (1996) Effects of a selective inhibitor of the Abl tyrosine kinase on the growth of Bcr-Abl positive cells. Nat Med 2:561-566.

Evans JM, Donnelly LA, Emslie-Smith AM, Alessi DR, Morris AD (2005) Metformin and reduced risk of cancer in diabetic patients. British Medical Journal 330: 1304-1305.

Genander M, Halford MM, Xu N-J, Eriksson M, Yu Z, Qiu Z, Martling A, Greicius G, Thakar S, Catchpole T, Chumley M, Zdunek S, Wang C, Holm T, Goff SP, Petterson S, Pestell RG, Henkemeyer M, Frisen J (2009) Dissociation of EphB2 signaling pathways mediating progenitor cell proliferation and tumor suppression. Cell 139:769-792.

Hochhaus A, Baccarani M, Deininger M, Apperley JF, Lipton JH, Goldberg SL, Corm S, Shah NP, Cervantes F, Silver RT, Niederwieser D, Stone RM, Dombret H, Larson RA, Roy L, Hughes T, Müller MC, Ezzeddine R, Countouriotis AM, Kantarjian HM (2008) Dasatinib induces durable cytogenetic responses in patients with chronic myelogenous leukemia in chronic phase with 
resistance or intolerance to imatinib. Leukemia 22: 1200-1206.

Huguet F, Giocanti N, Hennequin C, Croisy M, Touboul E, Favaudon V (2008) Growth inhibition by STI571 in combination with radiation in human chronic myelogenous leukemia K562 cells. Mol Cancer Ther 7:398-406.

Isakovic A, Harhaji L, Stevanovic D, Markovic Z, SumaracDumanovic M, Starcevic DM, Trajkovic V (2007) Dual antiglioma action of metformin: cell cycle arrest and mitochondria-dependent apoptosis. Cell Mol Life Sci 64:1290-1302.

Joensuu H, Roberts PJ, Sarlomo-Rikala M, Andersson LC, Tervahartiala P, Tuveson D, Silberman SL, Capdeville R, Dimitrijevic S, Druker B, Demetri GD (2001) Effect of the tyrosine kinase inhibitor ST1571 in a patient with metastatic gastrointestinal stromal tumor. N Engl J Med 344:1052-1056.

Kundu P, Genander M, Straat K, Classon J, Ridgway RA, Tan EH, Bjork J, Martiling A, van Es J, Sansom OJ, Clevers H, Petterson S, Frisen J (2015) An EphB-Abl signaling pathway is associated with intestinal tumor initiation and growth. Sci Transl Med 7(281):281ra44.

Lee JH, Kim TI, Jeon SM, Hong SP, Cheon JH, Kim WH (2011) The effects of metformin on the survival of colorectal cancer patients with diabetes mellitus. Int $\mathrm{J}$ Cancer 131:752-759.

Li H, Jin X, Zhang Z, Xing Y, Kong X (2013) Inhibition of autophagy enhances apoptosis induced by the PI3K/ AKT/mTor inhibitor NVP-BEZ235 in renal cell carcinoma cells. Cell Biochem Funct 31:427-433.

Mendoza MC, Er EE, Blenis J (2011) The RAS-ERK and PI3K-mTOR pathways: cross-talk and compensation. Trends Biochem Sci 36:320-327.

Mizushima N, Yoshimori T, Levine B (2010) Methods in mammalian autophagy research. Cell 140:313-326.

Nanglia-Makker P, Yu Y, Vasudevan A, Farhara L, Rajendra SG, Levi E, Majumdar AP (2014) Metformin: a potential therapeutic agent for recurrent colon cancer.
PLoS One 9(1):e84369.

Niehr F, Euw E, Attar N, Guo D, Matsunaga D, Sazegar H, Ng C, Glaspy JA, Recio JA, Lo RS, Mischel PS, CominAndix B, Ribas A (2011) Combination therapy with vemurafenib (PLX4032/RG7204) and metformin in melanoma cell lines with distinct driver mutations. J Transl Med 9:76-88.

Norbury C, Nurse P (1992) Animal cell cycles and their control. Trends Biochem Sci 19:143-145.

O’Hare T, Deiniger MWN, Eide CA, Clackson T, Druker BJ (2011) Targeting the BCR-ABL signaling pathway in therapy resistant Philadelphia chromosome-positive leukemia. Clin Cancer Res 17:212-221.

Park D, Lee Y (2014) Biphasic activity of chloroquine in human colorectal cacner cells. Dev Reprod 18:225-231.

Popow-Wozniak A, Wozniakowska A, Kaczmarek L, MalickaBlaszkiewicz M, Nowak D (2011) Apoptotic effect of imatinib on human colon adenocarcinoma cells: Influence on actin cytoskeleton organization and cell migration. Eur J Pharmacol 667:66-73.

Quinn BJ, Kitagawa H, Memmot RM, Gills JJ, Dennis PA (2013) Repositioning metformin for cancer prevention and treatment. Trends Endocrinol Metab 24(9):469-480.

Saglio G, Kim DW, Issaragrisil S, Coutre P, Etienne G, Lobo C, Pasquini R, Clark RE, Hochhaus A, Hughes TP, Gallagher N, Hoenekopp A, Dong M, Haque A, Larson RA, Kantarjian HM (2010) Nilotinib versus imatinib for newly diagnosed chronic myeloid leukemia. N Engl J Med 362:2251-2259.

Shaw RJ, Lamia KA, Vasquez D, Koo SH, Bardeesy N, Dpinho RA, Montminy M, Cantley LC (2005) The kinase LKB1 mediates glucose homeostasis in liver and therapeutic effects of metformin. Science 310:16421646.

Shi R, Lin J, Gong Y, Yan T, Shi F, Yang X, Liu X, Naren D (2015) The antileukemia effect of metformin in the Philadelphia chromosome-positive leukemia cell line and patient primary leukemia cell. Anti-Cancer Drugs 
26(9):913-922.

Song J, Kang JH, Kang HK, Kim K, Lee S, Choi D, Park D, Lee Y (2011) Mechanism of ethanol-induced Purkinje cell death in developing rat cerebellum: its implication in apoptosis and oxidative damage. Dev Reprod 15:205-213.

Stahtea XN, Roussidis AE, Kanakis I, Tzanakakis GN, Chalkiadakis G, Mavroudis D, Kletsas D, Karmanos NK (2007) Imatinib inhibits colorectal cancer cell growth and suppresses stromal-induced growth stimulation, MT1-MMP expression and pro-MMP2 activation. Int J Cancer 121:2808-2814.

Sui X, Chen R, Wang Z, Huang Z, Kong N, Zhang M, Han W, Lou F, Yang J, Zhang Q, Wang X, He C, Pan H (2013) Autophagy and chemotherapy resistance: A promising therapeutic target for cancer treatment. Cell Death Dis 4:e838.

Takeuchi H, Kondo Y, Fujiwara K, Kanazawa T, Aoki H, Mills GB, Kondo S (2005) Synergistic augmentation of rapamycin-induced autophagy in malignant glioma cells by phosphatidylinositol 3-kinase/protein kinase B inhibitors. Cancer Res 65:3336-3346.
Tomimoto A, Endo H, Sugiyama M, Fujisawa T, Hosono K, Takahashi H, Nakajima N, Nagashima Y, Wada K, Nakagama H, Nakajima A (2008) Metformin suppresses intestinal polyp growth in ApcMin/+ mice. Cancer Sci 99:2136-2141.

Wheaton WW, Weinberg SE, Hamanaka RB, Soberanes S, Sullivan LB, Anso E, Galsauer A, Dufour E, Mutlu GM, Budigner GRS, Chandel N (2014) Metfromin inhibits mitochondrial complex I of cancer cells to reduce tumorigenesis. eLife 3:e2242.

Wilcock C, Bailey CJ (1994) Accumulation of metformin by tissues of the normal and diabetic mouse. Xenobiotica 24:49-57.

Yang ZJ, Chee CE, Huang S, Sinicrope FA (2011) The role of autophagy in cancer: Therapeutic implications. Mol Cancer Ther 10:1533-1541.

Zhang J, Yang P, Gary N (2009) Targeting cancer with small molecule kinase inhibitors. Nature Rev Cancer 9:28-39.

Zhang Y, Guan M, Zheng Z, Zhang Q, Gao F, Xue Y (2013) Effects of metformin on $\mathrm{CD} 133+$ colorectal cancer cells in diabetic patients. PLoS One 8(11):e81264. 